\title{
What is a Knowledge-Rich Curriculum?
}

\author{
Elizabeth Rata
}

\section{University of Auckland}

A well-designed curriculum creates a knowledge-rich one. The application of the Curriculum Design Coherence Model (CDC Model) in the international Knowledge-Rich School Project is discussed to demonstrate the effectiveness of the Model as a design tool. It achieves coherence by connecting the three forms of subject knowledge: generalising concepts, materialised content and applied competencies. Concepts' generalisability creates knowledge's internal logic - the source of understanding (learning). Students only develop deep understanding when they work with generalising concepts. Thinking (learning) doesn't occur in a vacuum - one must think with something (concepts). And students also need to think about something (content). The article explains why it is essential to connect concepts and content. Such connection overcomes the limitations of both a 'big ideas' or concepts-only approach and a content-list approach. The CDC Model's connection of generalising concepts, materialised content and applied competencies also reveals why New Zealand's current competency-centred curriculum is inadequate. Two examples show how the CDC Model is used - a Physical Education topic 'Exercise' and a Social Studies topic, 'The History of Ngati Kuri.' Topics designed in the Knowledge-Rich School Project are mentioned.

Keywords: curriculum knowledge, curriculum design, knowledge-rich, CDC Model

\section{Introduction}

This article is a short introduction to the concept of a 'knowledge-rich' curriculum. Such a curriculum is the focus of the international Knowledge-Rich School Project, a project trialling the effectiveness of the Curriculum Design Coherence Model (CDC Model) as the design tool in developing a knowledge-rich curriculum. A full account of the KnowledgeRich School Project and the CDC Model is available in the Project Research Report (Rata, 2021a and b; see also McPhail, 2020; Rata, 2019). My main purpose here is limited to addressing the question: 'What makes curriculum knowledge 'rich'?' This requires explaining the realist theory of knowledge which a) informs the knowledge-rich curriculum approach, and b) shows how the CDC Model operates as the design tool for this approach. Following this discussion, I conclude by distinguishing 'knowledge-rich' from the 'knowledge-led' and 'knowledge-engaged' approaches identified in England (Spielman, 2018).

'Knowledge-rich' was the term I proposed for the type of curriculum for which the CDC Model is intended. It was subsequently used as the title for the research project trialling the CDC Model with six schools in Auckland and underway in a teacher education programme in England. My purpose in choosing 'rich' was to capture both the depth and breadth of the knowledge which constitutes school subjects. Designing such knowledge for its depth and breadth will lead to increased student understanding; (Rata, 2021a, section 5). This is the motive driving the Knowledge-Rich School project researchers. 


\section{Theory of knowledge}

Rational knowledge is produced in the mind and in the way those 'real' thought products (hence realism) connect to our material conditions of existence. The connection occurs as thought products are generalised to particular instances or content. Realism (often referred to as 'science') is informed by Kant's (1781) view that rational knowledge can only arise from the "united operation of both"; the mental and the material or the thought product (the generalisable concept) and its content. This connection is expressed in his famous dictum "Thoughts without content are empty" (1781, 1993, p. 69). (It is captured in the CDC Model's second Element; a point I discuss below.)

Theories and concepts developed in the 'mind-matter' connection are produced in the various disciplines of the sciences, social sciences, humanities, and arts and are subjected to accepted procedures of verification. They form what in the CDC model we call propositional knowledge or 'knowledge-that' (Ryle, 1949). In turn, 'knowledge-that' is altered for teaching as school subjects. Teachers first design the subject concepts and their connected content. Then they decide which skills and competencies need to be designed so that when the knowledge is taught, students will be able to put it into practice, using their 'know-how-to' skills and competencies.

The contribution of realist knowledge theory to the knowledge-rich curriculum more broadly and to the CDC Model specifically lies in four features of rational knowledge. The first feature is the generalisability of concepts. The second is the way in which this generalisability enables the concept-content connection to create 'knowledge-that' (i.e., propositional knowledge). The third is that this propositional knowledge is differentiated from the type of socio-cultural knowledge which is acquired from the experiences of our daily lives. The fourth is that the actual application of propositional knowledge in 'knowhow-to' skills follows from students acquiring 'knowledge-that'. Students are unable to apply the knowledge without first having the knowledge.

Realist theory allows us to see the central role of the generalisable concept in creating coherence between patterns of similar concepts (i.e., epistemic structures). Using concepts to generalise is the mechanism for designing a coherent curriculum therefore it is important to explain where the generalising function arises and how it occurs. The generalising process is set in motion when the thought (or idea or concept) become a 'real' object or product as it is separated from the original thinker (Popper, 1981). As a product it is no longer part of the thinking process but an object (or product) of thought. It is now available to others who can generalise it to understanding social and natural phenomena.

The separation of the thought product from the thinking process means that the knowledge is no longer subjective. As a thought object with generalisable properties which can be applied to understanding a range of instances, the concept is also universalisable - available to everyone. This universal property is the political imperative of education systems in democratic nations; an imperative which accepts that all children, no matter their background or circumstances, have a right to the type of knowledge which enables them to generalise beyond the confines of their experiences.

The CDC Model was developed within this broader democratic project. We acknowledge that disciplinary-derived knowledge is necessarily difficult knowledge because its generalisable property makes it remote from everyday socio-cultural knowledge. (See Geary \& Berch, 2016). Given the difficulty, we consider that the design of the knowledge is crucial. Therefore, the CDC Model's guiding principle is that school topics should be designed to capture the way similar generalising concepts are linked in 
increasingly complex patterns of meaning. We refer to these patterns of meaning as 'epistemic structures.'

The CDC Model's curriculum design makes visible to students the internal logic (or arrangement) in the knowledge's epistemic structure. Concepts which make up those structures become increasingly more complex as we advance through the school years. Because there is a direct connection between this logically structured knowledge and the development of a logically organised mind, using these epistemic structures enables us to think. In other words, epistemic structures are the mind's 'building blocks.' Engaging our minds with increasingly complex concepts enables us to think is more and more complex ways. This is not a new theory of the link between knowledge and learning. Indeed, the link has a long history. Plato recognised that concepts build our minds. He referred to the "acts of thinking (which are) the operations of considering propositions" (Plato cited in Ryle, 1949, p.1.: See also Rata, 2021a, section 5 for a detailed discussion of the link between the thought product and the thinking process (i.e., learning).

\section{Knowledge-rich: Depth and breadth}

I mention above how epistemic structuration occurs as concepts are brought together to give depth and breadth to a topic; the source of the 'richness'. These patterns of generalising concepts serve as the mechanism for coherence in a subject's topics. For example, in Physical Education, a school subject which derives many of its concepts from the bio-science disciplines, the epistemic structure for the topic 'exercise' would select concepts specific to that topic. These may include 'muscles', 'energy', 'stamina', and 'endurance'. Each concept deepens the meaning of the others by drawing out their inherent connection.

Another example of the role of concepts in building epistemic structures is from the Knowledge-Rich School Project. The social studies topic is 'the History of Ngati Kuri' and the subject concepts selected were 'settlement', 'displacement', and 'revival'. I refer above to Kant's dictum that "concepts without content are empty" and the need for the "united operation" with the term 'knowledge-that' standing for the concepts - content connection. The connection brings together each component's distinct functions; generalisability in the case of concepts and as evidence for the concepts in the case of content. In the Ngati Kuri topic, that 'united operation' providing depth and breadth occurred as the proposed concepts 'settlement', 'displacement', and 'revival' were connected to content.

The issue of what content is central to the veracity of the knowledge. The Ngati Kuri topic contained a plethora of evidence from numerous verifiable primary and secondary historical sources. This was to demonstrate that, in designing a topic, there must be sufficient evidence to ensure that the connection of concepts and content does create reliable and truthful knowledge. It was not enough for the topic designer to propose or claim that Ngati Kuri has experienced 'settlement', 'displacement' and revival'. (See below for the role of the proposition in doing this 'proposing'.) The job of the concept-content connection is to establish the truthfulness of the proposition and that requires content which provides evidence of the concepts, thereby justifying their use. Because content selection is essential to the concept-content connection Element 2 of the CDC Model has three criteria for justifying the selection (McPhail, 2020; Rata, 2019). This meets Plato's requirement (in the Dialogue, Meno section 98) that rational (i.e., propositional) knowledge comes about by the mind giving its beliefs sufficient evidence.

The Ngati Kuri design example also enables me to draw attention to the importance of beginning curriculum design by starting with a lesson or topic before building a 
cumulative year long course or an across the years' programme. Starting with the smallest design unit (the topic), ensures the specificity of concepts as well as content. In order to reinforce the need for specific concepts in curriculum design the CDC Model uses the term 'subject concepts' rather than 'concepts' alone. This rather pedantic requirement keeps attention on the epistemic structure of concepts; that is, they are built according to the concepts' logical relationships. They are not random ideas but are contained (i.e., disciplined or structured, or patterned) within disciplinary-derived boundaries. Therefore, the concepts 'belong' to the subjects, and at the smallest unit, to the topic within that subject. This is an important idea because the linking of subject concepts into logical patterns within epistemic structures, something only possible because the concepts are generalisable, provides the coherence underpinning the knowledge in any particular subject.

\section{The Curriculum Design Coherence Model}

Figure 1 provides a diagram of the CDC Model with four elements. Element 1 includes 'selecting the subject concepts.' (Note: this discussion is limited to elements 1 and 2 only)

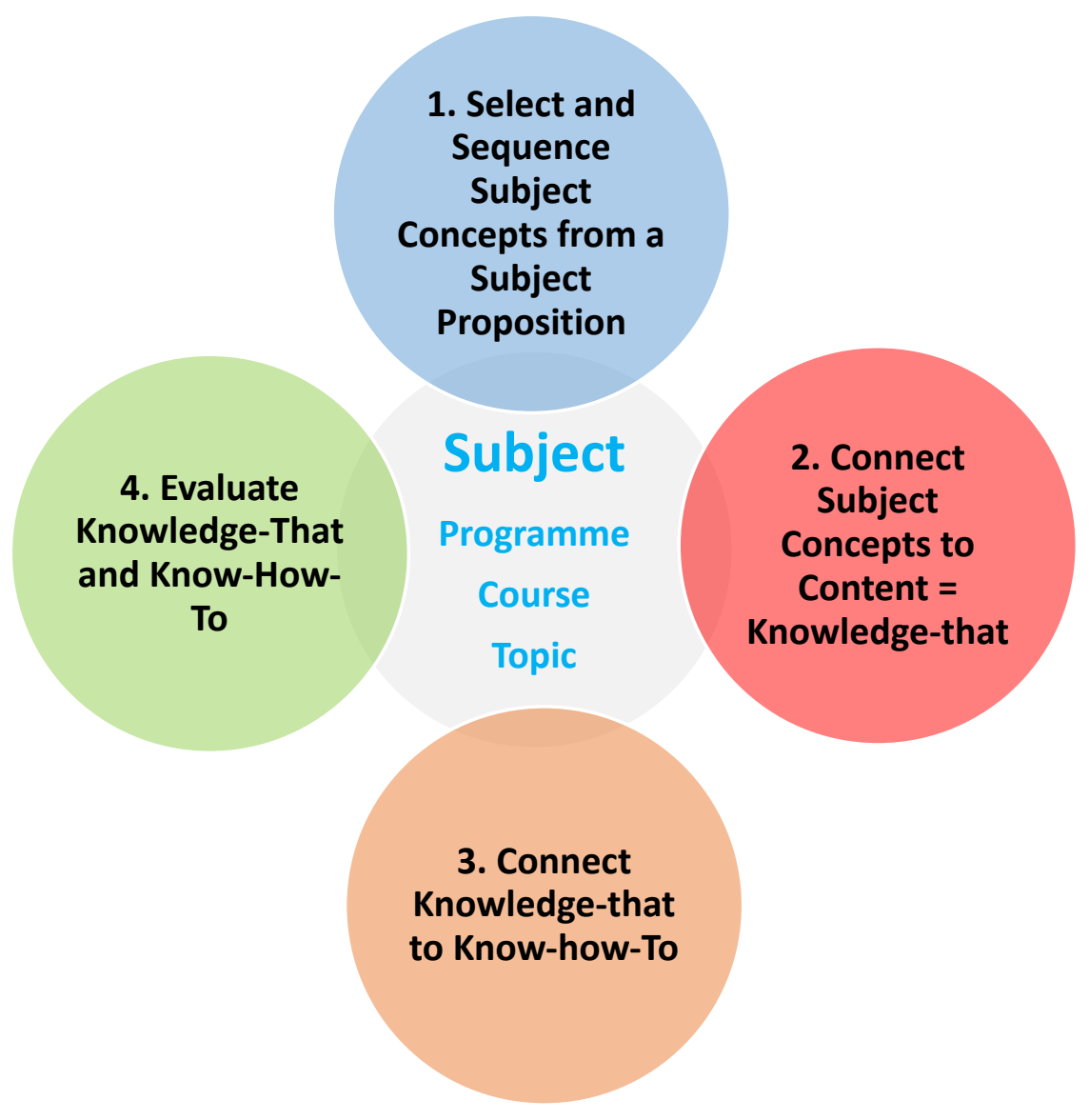

Figure 1. The Curriculum Design Coherence Model (Elizabeth Rata) 


\section{Meaning and the CDC Model's proposition}

This section discusses how the Model's proposition establishes the topic's meaning which in then able to be generalised by connecting the concepts to the topic's particular instance in a 'united operation'. The placement of subject concepts in the Model's first element recognises their primary role in curriculum design. I have described above how concepts' generalisability makes them the source of knowledge's rich 'depth' and 'breadth'. It is also the source of learning. Students develop the intellectual means to think about what concepts mean because they are working with generalisable concepts in the first place. Thinking (i.e., learning) doesn't occur in a vacuum - one must think with something (concepts). And students also need to think about something (content). This is where the concept-content connection of the Model's Element 2 is brought into play as the content (the particular instance or object of the conceptual thought) enables the concept to be generalised to the material object.

Connecting subject concepts to content is well and good but why? What are those connections to mean to students? This is where the CDC Model proposition mentioned in Element 1 plays its role in stating what the topic is to mean to the students. Meaning is found in the relationship of concepts to the topic and it is the task of the proposition to propose (claim, assert, or state) what that meaning is. To refer to the 'the History of Ngati Kuri' again; the proposition for this topic states 'Ngati Kuri, has experienced settlement, displacement, and revival'. The verb 'experienced' contains the proposed relationship between the subject of the proposition, 'Ngati Kuri' and the concepts of 'settlement', 'displacement', and 'revival' found in the sentence's predicate.

A proposition's grammar is the linguistic form which enables the proposed relationship to be 'seen'. According to Frege (cited in Carr, 2010) because of the "function of the grammatical interplay of reference and predication: we should never ask for the meaning of a word in isolation but only in the context of a proposition" (p. 45). The proposition is crucial to the CDC Model for this reason. It allocates meaning to the topic, a meaning established by the verb in stating the nature of the relationship between the topic and the concepts. The content's task is to provide the evidence. By bringing the proposed meaning to the surface, the veracity of a topic is available for scrutiny. It is a way to ensure that the knowledge taught to students is verifiable and reliable and not merely the opinion or beliefs of the teacher.

The proposition statement serves as the design fulcrum. By connecting the topic to the key subject concepts, it begins the process of, and provides the frame for, design coherence. Teachers and researchers in the Knowledge-Rich School Project have written numerous propositions for a variety of topics in a number of subjects. They include: (I have italicised the verb which makes the assertion or proposal.) 'The apostrophe is a grammatical marker of possession or contraction.' 'The English alphabet is the order of 26 symbols used in writing.' 'Metallic bonding is the structuring of free electrons among positively charged metal ions.' 'Monet's style exhibits Impressionist subject matter, spontaneity, colour, light effects, and painting technique.' 'Tutin, the poison of the tutu plant, is identified by its molecular structure and chemical formula.' 'Chant is a musical form using voices with a limited pitch range and rhythm generated by the text.'

\section{Conclusion: Knowledge-led and knowledge-engaged}

In the past decade, several countries, including England, Australia, and South Africa, have moved away from the limitations of the outcomes-based, competency approach for a greater emphasis on subject knowledge. In this they share the intention of the knowledge- 
rich approach - to ensure that disciplinary-derived knowledge is the central purpose of schooling. However, the renewed focus on knowledge has had unintended outcomes. Spielman (2018) refers to the 'knowledge-led' category appearing in some schools in England - a content-list approach with students taught plenty of content but without the coherence provided by subject concepts. Without the generalising and cohering function of connected subject concepts, the unanchored content becomes fragmented and meaningless.

Another knowledge approach which has unintended consequences is the 'big ideas' one; referred to by Spielman (2018) as 'knowledge-engaged'. This does recognise the importance of concepts, but they tend to be generic, unanchored to the content which would provide evidence of their meaning. The absence of a specific subject 'anchor' for these concepts means that they can mean everything and anything. There is no proposition to link the concepts to a topic and no requirement for content to express the concept's generalising function. This is the space for ideology to enter the curriculum.

In conclusion, the 'knowledge-rich' curriculum seeks to address the limitations of both the knowledge-led and the knowledge-engaged approaches by using the CDC Model as a design tool to connect generalisable concepts to particular instances. This is the 'knowledge-that' of Elements 1 and 2 in the Model. Element 3 (which I have not described in this short piece) moves away from the knowledge itself to the 'know-how-to,' that is to the application of the 'knowledge-that' in skills and competencies. However, before knowledge is applied, the knowledge itself must be known. Designing the curriculum first before proceeding to its practice applies to teaching as to everything else. Teachers need to be experts in the subjects they teach so they can design 'knowledge-that' by connecting a topic's concepts to the content in Kant's united operation. Once the knowledge has been designed in this way then the 'know-how-to' of the actual teaching can occur.

\section{References}

Carr, D. (2010). Learning: Meaning, language and culture. In Arthur, J. and Davies, I. (Eds.), The Routledge Education Studies Reader. (pp. 37-51). London: Routledge.

Geary, D. \& Berch, D. B. (2016) Evolutionary perspectives on child development and education. Basel: Springer.

Kant, I. (1781/1993). Critique of Pure Reason. London \& Vermont: Everyman, J.M. Dent \& Charles E. Tuttle. Introduction by Vasilis Politis.

McPhail, G. (2020) The Search for deep learning: A curriculum coherence model. Journal of Curriculum Studies. http://dx.doi.org/10.1080/00220272.2020.1748231

Popper, K. (1981) Objective knowledge: An evolutionary approach (Rev. ed.). Oxford: Oxford University Press.

Rata, E. (2012) The Politics of knowledge in education. London: Routledge.

Rata, E. (2021a). The Curriculum Design Coherence Model in the Knowledge-Rich Schoool Project. Review of Education. https://doi.org/10.1002/rev3.3254 
Rata, E. (2021b) Context and Implications Document for The Curriculum Design Coherence Model in the Knowledge-Rich Schoool Project. Review of Education. https://doi.org/10.1002/rev3.3253

Rata E., McPhail G. (2020) Teacher Professional Development, the Knowledge-Rich School Project and the Curriculum Design Coherence Model. In: Fox J., Alexander C., Aspland T. (Eds.) Teacher Education in Globalised Times. Singapore: Springer.

Rata, E. (2019). Knowledge-Rich Teaching: A Model of Curriculum Design Coherence, British Educational Research Journal, (45)4, 681-697. https://doi.org/10.1002/berj.3520

Ryle, G. (1945) Knowing how and knowing that: The presidential address, Proceedings of the Aristolelian Society, New Series, 46(1945-1946), 1-16.

https://www.jstor.org/stable/4544405?seq=1

Spielman, A. (2018) $\mathrm{HMCl}$ commentary: curriculum and the new education inspection framework. https://www.gov.uk/government/speeches/hmci-commentary-curriculumand-the-new-education-inspection-framework Updated, 21 September. Retrieved 1 May 2020

Professor Elizabeth Rata is the Director of the Knowledge in Education Research Unit (KERU) in the School of Critical Studies in Education, Faculty of Education and Social Work at the University of Auckland. She publishes in the fields of curriculum knowledge, pedagogy, educational politics and policy, higher education, realist methodology, ethnicity in education, and culturalist ideology.

Email: e.rata@auckland.ac.nz

ORCiD: https://orcid.org/0000-0003-1918-6792 